\title{
A Systematic Review and Meta-Analysis of Gene Expression Profiling for Primary Cutaneous Melanoma Prognosis
}

\author{
Graham H. Litchman, DO, MS¹, Giselle Prado, MD¹, Rebeca W. Teplitz, DO², Darrell S. Rigel, \\ $\mathrm{MD}, \mathrm{MS}^{3}$
}

${ }^{1}$ National Society for Cutaneous Medicine, New York, NY

${ }^{2}$ New York Institute of Technology, College of Osteopathic Medicine, Old Westbury, NY

${ }^{3}$ Ronald O. Perelman Department of Dermatology, NYU Grossman School of Medicine, New York, NY

\section{ABSTRACT}

To decrease morbidity and mortality from melanoma, it is imperative to identify patients who are at high risk for developing widespread disease. Gene expression profiling (GEP) technology may impact melanoma management as physicians are better equipped to measure prognosis. Many different GEP signatures have been investigated. We searched Pubmed, Cochrane CENTRAL, and Embase for studies on GEP in primary melanoma prognosis and assessed GEP signatures for prognostic and analytic validity and clinical impact. The relationship between GEP and survival was measured using hazard ratios (HR) and odds ratios $(\mathrm{OR})$. We found twenty-nine articles comprising 9 gene signatures meeting inclusion criteria and conducted a meta-analysis on 6 studies on a 31-gene signature. High-risk GEP status was associated with poorer recurrence-free survival $(\mathrm{HR}=7.22 ; 95 \% \mathrm{Cl}, 4.75-10.98)$, distant metastasis-free survival ( $\mathrm{HR}=6.62 ; 95 \% \mathrm{Cl}, 4.91-8.91)$, and overall survival $(\mathrm{HR}=7.06 ; 95 \% \mathrm{Cl}$, 4.44-11.22); as well as sentinel lymph node biopsy positivity (OR=2.99; $95 \% \mathrm{Cl}, 2.15-4.15)$. With recent improvements in treating advanced melanoma, accurately assessing prognosis is important. This study has clinical implications for melanoma patients who may benefit from prognostic testing. These results may be useful to clinicians when ordering GEP testing and help them make better management decisions.

\section{INTRODUCTION}

Melanoma has the highest mortality among all skin cancer types. There will be an estimated 96,000 new cases of melanoma diagnosed in 2019 and over 7,000 deaths. ${ }^{1}$ Assessment of prognosis is critical in melanoma management. Management plans may influence survival outcomes depending on whether less frequent intervention or more aggressive follow up is chosen. Therefore, clinicians should be knowledgeable in issues critical to an accurate assessment of melanoma prognosis to achieve optimal patient management.

Gene expression profiling (GEP) is one form of genomic testing that can be used immediately after diagnosis to prognosticate melanoma outcomes. GEP samples RNA and DNA from a lesion to assess genetic characteristics, and the results can be used to guide further management. Several GEP tests have been described in the literature and some are commercially available. May 2020 Volume 4 Issue 3 
However, no studies have summarized the available evidence on GEP for prognosis in melanoma. As this field is rapidly evolving, the purpose of this systematic review and meta-analysis was to consolidate the body of data on GEP in melanoma prognosis.

\section{RESULTS}

A total of 672 articles were identified through database searching. (Figure 1) After the exclusion of duplicate references, 600 abstracts were screened, and 74 full-text articles and abstracts were retrieved. After then applying selection criteria, 29 articles were included in the systematic review.

\section{SYSTEMATIC REVIEW}

Nine unique gene signatures were reported. (Table 1)

\section{Gene}

In Alonso et al., 34 archival melanoma samples with a mean follow-up time of 67 months were analyzed. ${ }^{2}$ They found 206 upregulated and 37 downregulated genes that were differentially expressed based on nodal status. The authors classified these genes based on the mechanism of action or biological function and decided to focus on genes related to epithelial-mesenchymal transition (EMT). Then 127 archival samples with a mean follow-up time of 117 months were analyzed to determine which EMT genes were significantly associated with relapse-free survival (RFS). In univariate analysis, N-cadherin, osteonectin, and osteopontin expression were significantly associated with an increased incidence of metastases. However, when adjusted by Breslow depth, these associations were no longer significant. In multivariate analysis,
Protein Kinase $\mathrm{C} \alpha(\mathrm{PKC} \alpha)$ expression was significantly associated with RFS.

\section{Gene}

Winnepenninckx et al. was an early study to identify new prognostic markers using GEP on cutaneous melanoma samples. ${ }^{3}$ It found 254 genes associated with prognosis. Most of these genes were previously known to be correlated with thickness, but eight novel prognostic genes were identified. In a multivariate model adjusted for thickness, ulceration, age, and sex, the differential expression of 2 proteins were significantly associated with overall survival (OS).

\section{Leeds Cohort Sample}

Conway et al. analyzed 156 primary melanomas in a training set and 198 melanomas in a validation set to determine prognostic markers. ${ }^{4}$ They found that increased expression of osteopontin was a significant predictor of shorter RFS in both unadjusted $(\mathrm{HR}=3.17 ; 95 \% \mathrm{Cl}, 1.91-5.26)$ and adjusted analyses $(\mathrm{HR}=3.33 ; 95 \% \mathrm{Cl}$, 1.96-5.67).

Jewell et al. ${ }^{5}$ completed a follow-up study to Conway et al. ${ }^{4}$ and identified a group of DNA repair and associated genes that are overexpressed in patients with poor RFS. RAD52 and TOP2A (both DNA repair genes) were independent predictors of poor RFS. Their observations support previous studies that suggest melanoma cells need to maintain genomic integrity in order to continue aggressive division.

\section{2 or 4 Subtype Signature}

Harbst et al. ${ }^{6}$ retrospectively analyzed a cohort of 223 primary melanomas for correlation with the 4 gene subclasses previously discovered by Jonsson et al. ${ }^{7}$ Using the 4-class signature, the melanomas were classified as high-immune (57), normallike (63), pigmentation (84), and proliferative (16). Further analysis revealed 2 primary

May 2020 Volume 4 Issue 3 
Figure 1. PRISMA Flow Chart of Search Strategy.

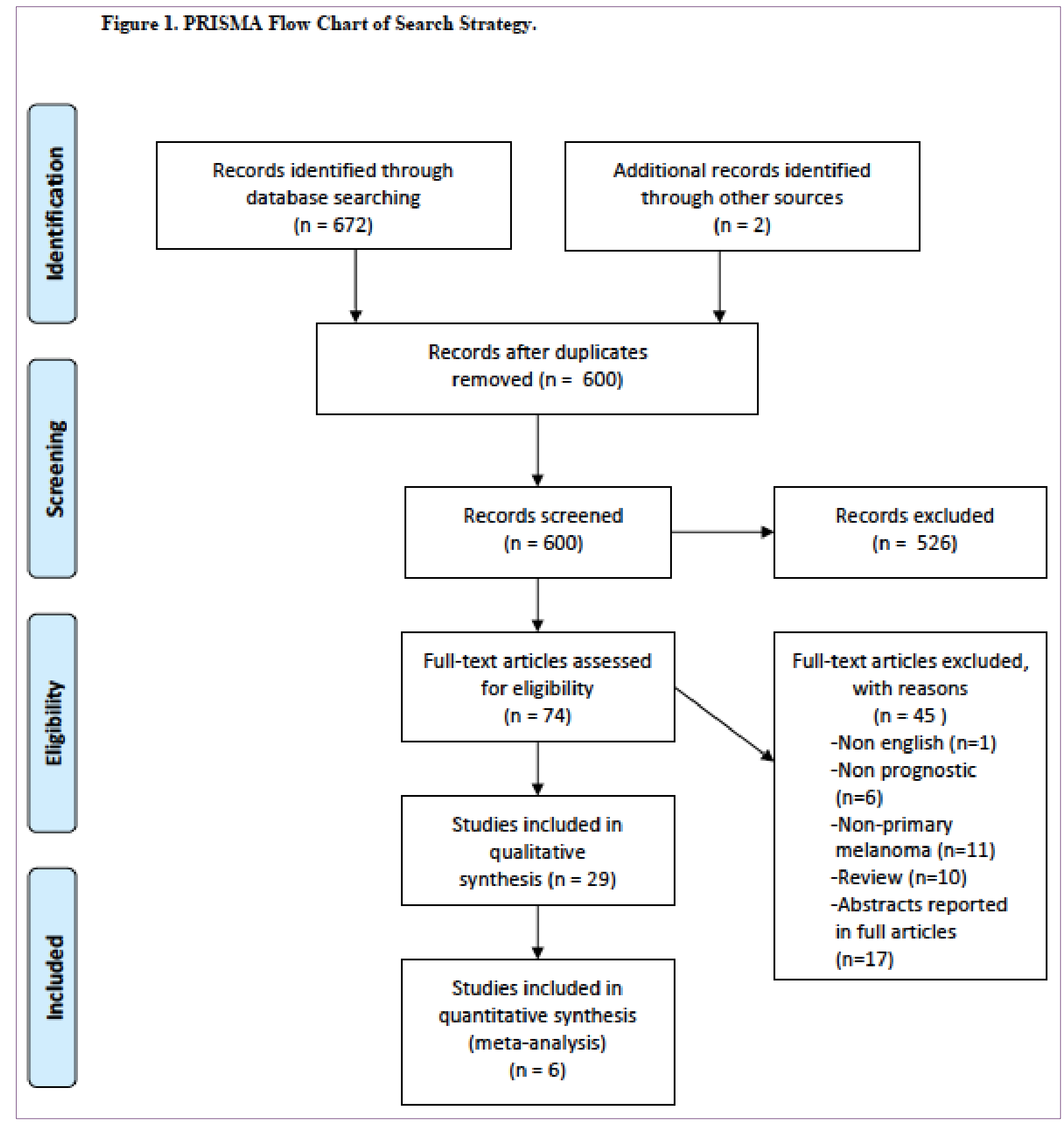

May 2020 Volume 4 Issue 3 
Table 1. Gene signatures reported in the literature.

\begin{tabular}{|c|c|}
\hline Gene Signature & Author \& Year \\
\hline $\begin{array}{l}243 \text { Differentially } \\
\text { Expressed Genes }\end{array}$ & Alonso $2007^{2}$ \\
\hline $\begin{array}{l}254 \text { Differentially } \\
\text { Expressed Genes }\end{array}$ & Winnepenninckx $2006^{3}$ \\
\hline Leeds Cohort Sample & $\begin{array}{l}\text { Conway } 2009^{4} \\
\text { Jewell } 2010^{5}\end{array}$ \\
\hline 2 or 4 Subtype & $\begin{array}{l}\text { Harbst } 2012^{6} \\
\text { Nsengimana } 2015^{8}\end{array}$ \\
\hline 2 Subtype & Badal $2017^{9}$ \\
\hline 7 Gene & Meyer $2012^{10}$ \\
\hline 9 Gene & $\begin{array}{l}\text { Brunner } 2013^{11} \\
\text { Brunner } 2018^{12}\end{array}$ \\
\hline 31 Gene & $\begin{array}{l}\text { Analytic Validity } \\
\text { Cook } 2018^{14} \\
\text { Clinical Management } \\
\text { Berger } 2016^{15} \\
\text { Cook } 2017^{18} \\
\text { Dengel } 2017^{16} \\
\text { Farberg } 2017^{19} \\
\text { Schuitevoerder } 2018^{17} \\
\text { Svoboda } 2018^{20} \\
\text { Prognostic Validity } \\
\text { Gerami } 2015^{21} \\
\text { Gerami } 2015^{22} \\
\text { Cook } 2017^{23} \\
\text { Ferris } 2017^{24} \\
\text { Hsueh } 2017^{27} \\
\text { Huang } 2017^{29} \\
\text { Keller } 2017^{28} \\
\text { Cook } 2018^{30} \\
\text { Greenhaw } 2018^{26} \\
\text { Keller } 2018^{31} \\
\text { Zager } 2018^{25}\end{array}$ \\
\hline 53 Gene & Sivendran $2014^{13}$ \\
\hline
\end{tabular}

forms of tumors: high-grade (proliferative/pigmentation) and low-grade (high-immune/normal-like). High-grade tumors were significantly more likely to have lower RFS (HR=4.94; 95\% Cl, 2.84-8.59) and lower overall survival $(\mathrm{HR}=3.66 ; 95 \% \mathrm{Cl}$, $2.40-5.58)$. Nsengimana et al. ${ }^{8}$ sought to independently replicate the gene signatures reported in Harbst et al. ${ }^{6}$ on the Leeds Cohort Sample 4 . The sample included 300 archival melanomas with differing prognosis (228 primaries, 76 metastases). Using the 4-class signature, the melanomas were classified as high-immune (70), normal-like (75), pigmentation (76), proliferative (37), and unclassified (12). Applying the 2-class signature, there were 135 high-grade lesions, 108 low-grade lesions, and 57 unclassified lesions. All molecular subtypes were correlated with AJCC stage, Breslow depth, ulceration, and mitotic rate. MSS analysis showed that even after adjusting for AJCC stage, molecular signature and presence of vascular invasion were independent prognostic factors.

\section{Subtype}

Badal et al. analyzed 78 archival melanocytic tumors (27 nevi, 51 melanoma) with a mean OS of 90 months. ${ }^{9}$ Transcriptional profiling revealed 4,639 genes that were differentially expressed in nevi and melanoma. The authors found significantly increased expression of immune- and inflammatoryrelated genes and significant repression of endogenous viral elements in melanomas. They also discovered a distinct 122 gene epigenetic signature that varied between aggressive and better prognosis melanomas. The aggressive melanomas were enriched in genes involved in cell proliferation and repressed in genes involving oncogenic signaling pathways (e.g. TP53, TP63, TP73). The high-risk epigenetic gene signature was an independent prognostic indicator for OS.

\section{Gene}

Meyer et al. developed a 7 gene molecular profile predictive of high or low metastatic risk among Stage I-II patients using a training sample of 362 primary melanomas and validated on an independent cohort of 225 primary melanomas. ${ }^{10}$ The gene signature included 7 biomarkers: Bax, Bcl-X, PTEN, COX-2, loss of b-Catenin, loss of MTAP, and presence of CD20 positive B-lymphocytes. The high-risk gene signature was associated with shorter median OS (88 months vs. not 
reached; $p<0.00001)$ and shorter median RFS (33 months vs. 88 months; $p<0.001$ ).

\section{Gene}

Brunner et al. first published a retrospective cohort of archival melanomas $(n=135)$ where gene signature was correlated with OS. ${ }^{11}$ Gene signature predicted $O S$ independently of AJCC staging ( $\mathrm{HR}=3.83 ; \mathrm{p}=0.0004)$. When combining AJCC staging and the 9 gene signature, patients in intermediate AJCC risk were reclassified into high- or low-risk groups.

In a more recent study, Brunner et al. describe a retrospective cohort of thin melanomas $(n=111)$ and melanomas with known SLN status $(n=203) .{ }^{12}$ High-risk 9GEP had a sensitivity of $33 \%$ for thin melanomas. GEP status and SLN status were significant independent prognostic factors for RFS.

\section{Gene}

Sivendran et al. developed a 53 gene panel that is predictive of RFS and DSS in stage IIIII patients. ${ }^{13}$ The authors used a training sample of 40 primary melanomas and screened 446 genes until narrowing down to the 53 gene panel. In both univariate and multivariate analysis, the 53 gene signature correlated with both RFS and DSS $(p<0.001)$. The 53 gene panel was then validated on 48 primary melanomas. Similar to the training set, Cox univariate analysis found that the 53 gene signature correlated with RFS and MSS. On multivariate analysis, it correlated with MSS only.

\section{Gene}

The 31 gene signature test was the most widely studied in the literature. For clarity, studies related to the 31 gene signature are subdivided into analytic validity, clinical management, and prognostic validity.

\section{Analytic Validity}

Cook et al. reported an inter-assay concordance of $99 \%$, inter-instrument concordance of $95 \%$, and inter-operator concordance of $100 \%$ for 31 -GEP. ${ }^{14} 85 \%$ of specimens fulfilled minimum tumor content requirements, and technical success was $98 \%$.

\section{Clinical Management}

Berger et al. published a retrospective chart review that determined the impact of 31-GEP results on clinical decisions including follow up frequency, imaging ordered, SNLB, and referral to oncologists. ${ }^{15} 156$ patients were included (95 low-risk, and 61 high-risk). A change in management after 31 -GEP testing was seen in $53 \%$ of patients (37\% of low-risk, $77 \%$ of high-risk). Most of these management changes were concordant with the risk indicated by the test, i.e. high-risk patients resulted in increased intensity of management and vice versa. However, this study did not follow-up with patient outcomes.

In a patient outcomes study, 63 stage 1B/IIA melanoma cases who underwent 31-GEP testing were analyzed for changes from surveillance to routine imaging frequency for 2 years. ${ }^{16}$ Of the 13 high-risk patients, 12 were upgraded to routine imaging.

A retrospective chart review showed that 31GEP status was significantly associated with the clinical management of Stage I and II CM patients. ${ }^{17}$ Stage 1/low-risk patients were more likely to be managed by dermatologists alone, while stage $2 /$ high-risk patients were more likely to be followed by surgical oncology.

A survey of 157 dermatologists who were presented 1 clinical scenario without GEP information, but with a low- and high-risk result, found that respondents tended to choose a higher threshold Breslow thickness 
to order sentinel lymph node biopsy (SLNB), imaging, or recommend referral if given a low-risk result. ${ }^{18}$ This corresponded with a lower threshold Breslow thickness with a high-risk result.

With the same study design as Cook et al. ${ }^{19}$, a survey of 169 dermatology residents found that most respondents changed their recommendation for SLNB, imaging, and referral in the risk appropriate direction after being given GEP results. ${ }^{19,20}$

Another survey of 181 dermatologists found that ulceration in thin lesions was the most important factor to impact a dermatologist's decisions to order the 31-GEP test. ${ }^{20}$

\section{Prognostic Validity}

Gerami et al. reported the initial validation study of 31-GEP using a training set of 164 cases and a validation set of 104 cases with a minimum 5 year follow up. ${ }^{21}$ In multivariate analysis, a high-risk GEP result was associated with a 9.5 times increased risk of developing any type of metastasis or locoregional recurrence. 31-GEP status was an independent predictor of metastatic risk similar to AJCC stage, Breslow depth, ulceration, and age.

In a retrospective cohort of 217 patients who had undergone SLNB and had a minimum 5year follow-up, 31-GEP status was more predictive than SLNB for all endpoints (RFS, DMFS, and OS). ${ }^{22}$

An analysis of 782 primary CM found that 31 GEP status was a significant predictor of RFS, DMFS, OS, and MSS risk $(p<0.05) .{ }^{23}$ 31-GEP class had a sensitivity of $76 \%$, specificity of $67 \%$, NPV of $91 \%$, and PPV of $39 \%$ for distant metastases occurrence.

Ferris et al. studied 205 patients with early stage CM and evaluated both 31-GEP status and AJCC prediction. ${ }^{24}$ Combining 31-GEP results with AJCC predication accurately identified $90 \%$ of recurrences, $88 \%$ of distant metastases, and $82 \%$ of deaths.

Zager et al. studied $523 \mathrm{CM}$ cases and found that 31-GEP status was a significant independent predictor of RFS and DMFS in both univariate and multivariate analyses. ${ }^{25}$

An independent validation study of the 31GEP test on 256 patients with Stage I-II melanoma found high sensitivity, specificity, and NPV. ${ }^{26}$ MFS curves for this study and the Gerami cohort ${ }^{21}$ were closely correlated.

In a prospective cohort study of 322 realworld patients, Hsueh et al. found that highrisk GEP result was a stronger predictor of RFS than positive SLNB (HR=7.15 vs. 2.46). ${ }^{27}$ However, the GEP result was not a significant predictor of DMFS or OS.

Keller et al. sought to determine whether 31GEP status could be used to predict SLNB positivity by enrolling 163 patients into a prospective cohort study. ${ }^{28}$ Within the 15 high-risk 31-GEP patients, only 3 patients had a positive SLNB. 31-GEP status was not a significant predictor of SLNB positivity in stage 1 or 2 . The authors concluded that 31GEP status should not be a substitute for SLNB in staging melanoma patients.

In a retrospective cohort study of 128 melanomas, Huang et al. found that high risk 31-GEP was a better predictor of SLNB positivity than Breslow thickness, ulceration, and mitotic rate. ${ }^{29}$ This suggests that obtaining GEP status prior to definitive surgical planning may be beneficial when SLNB is not indicated by traditional pathologic variables.

The combination of 31-GEP class and nonsentinel lymph node status was able to 
identify most patients (87\%) who would experience distant metastases. ${ }^{30}$ The highest sensitivity for distant metastases was achieved by combining lymph node status and 31-GEP results.

Keller et al. also evaluated the use of 31-GEP in identifying patients with non-sentinel node (NSN) metastases. In a cohort of 287 patients, 39 had positive SLNB. ${ }^{31}$ Among the positive SLNB patients, 8 also had positive NSN. 7/8 NSN positive patients had higher risk GEP status. In chi-square analysis, GEP status was a significant predictor of NSN metastases $(p=0.0047)$.

\section{META-ANALYSIS}

Due to heterogeneity among reported gene signatures and paucity of reported studies for the different GEP tests, the meta-analysis conducted was limited to data from the 31gene signature consisting of 6 studies on prognostic validity. ${ }^{24,26-30}$ (Table 2) A funnel plot did not show evidence of publication bias. For 31-gene, the pooled HR for RFS was 7.22 (95\% Cl, 4.75-10.98). (Figure 2a) However, there was significant heterogeneity seen between studies. The pooled HR for DMFS was 6.62 (95\% Cl, 4.91-8.91). (Figure 2b) The pooled HR for OS was $7.06(95 \% \mathrm{CI}$, 4.44-11.22). (Figure 2c)

Pooled ORs were calculated for recurrence, distant metastases development, overall survival, and SNLB positivity. The pooled OR for recurrence was $9.42(95 \% \mathrm{Cl}$, 5.8415.20). (Figure 3a) There was also significant heterogeneity seen between studies for this outcome. The pooled OR for distant metastases was $7.93(95 \% \mathrm{Cl}, 4.98-12.64)$. (Figure 3b) The pooled OR for overall survival was $6.43(95 \% \mathrm{Cl}, 3.90-10.61)$. (Figure 3c)
The pooled OR for SLNB positivity was 2.99 $(95 \% \mathrm{Cl}, 2.15-4.15)$. (Figure 3d)

Table 2. Studies included in meta-analysis.

\begin{tabular}{|c|c|c|c|c|}
\hline $\begin{array}{l}\text { Author \& } \\
\text { Year }\end{array}$ & $\begin{array}{l}\text { Sample } \\
\text { Size }\end{array}$ & $\begin{array}{l}\text { Age in } \\
\text { Median } \\
\text { Years } \\
\text { (range) }\end{array}$ & Stage & $\begin{array}{l}\text { Median } \\
\text { Follow- } \\
\text { Up in } \\
\text { Years } \\
\text { (Range) }\end{array}$ \\
\hline $\begin{array}{l}\text { Gerami } \\
2015^{22}\end{array}$ & 217 & $\begin{array}{l}61(23- \\
94)\end{array}$ & $\begin{array}{l}\text { I:46 } \\
\text { II:112 } \\
\text { III:58 } \\
\text { IV:1 }\end{array}$ & $\begin{array}{l}\text { Not } \\
\text { Reporte } \\
\text { d }\end{array}$ \\
\hline $\begin{array}{l}\text { Ferris } \\
2017^{24}\end{array}$ & 205 & $\begin{array}{l}61(18- \\
89)\end{array}$ & $\begin{array}{l}\text { I: } 109 \\
\text { II: } 96\end{array}$ & $\begin{array}{l}6.9(0.1- \\
15.4)\end{array}$ \\
\hline $\begin{array}{l}\text { Hsueh } \\
2017^{27}\end{array}$ & 322 & $\begin{array}{l}58(18- \\
87)\end{array}$ & $\begin{array}{l}\text { None } \\
: 3 \\
\text { I:209 } \\
\text { II:73 } \\
\text { III:36 } \\
\text { IV:1 }\end{array}$ & 1.5 \\
\hline $\begin{array}{l}\text { Keller } \\
2017^{28}\end{array}$ & 163 & $\begin{array}{l}\text { Not } \\
\text { reported }\end{array}$ & $\begin{array}{l}\mathrm{T} 1: 7 \\
2 \\
\mathrm{~T} 2: 9 \\
1\end{array}$ & $\begin{array}{l}\text { Not } \\
\text { reported }\end{array}$ \\
\hline $\begin{array}{l}\text { Greenha } \\
\text { w } 2018^{26}\end{array}$ & 256 & 69 & $\begin{array}{l}\text { I:219 } \\
\text { II:24 }\end{array}$ & $\begin{array}{l}23 \\
\text { months }\end{array}$ \\
\hline $\begin{array}{l}\text { Zager } \\
2018^{25}\end{array}$ & 244 & $\begin{array}{l}59(18- \\
92)\end{array}$ & $\begin{array}{l}\text { I:264 } \\
\text { II:93 } \\
\text { III:16 } \\
6\end{array}$ & $\begin{array}{l}7.5(5.0- \\
16.5)\end{array}$ \\
\hline
\end{tabular}

\section{DISCUSSION}

Commercially available GEP tests are already impacting physician management decisions in real-world patients. ${ }^{17-22}$ Through integrating this technology, physicians are now better positioned to counsel their melanoma patients regarding prognosis.

With the recent improvements in treating advanced disease, accurately assessing prognosis is particularly important. A patient's prognosis affects a clinician's intensity of management. In the near future, clinicians may recommend immunotherapy for early stage high-risk patients. GEP testing in this context could potentially play a significant 
Figure 2. Forest plot of hazard ratio and $95 \% \mathrm{Cl}$ for (a) recurrence free survival, (b) distant metastasis free survival, and (c) overall survival.

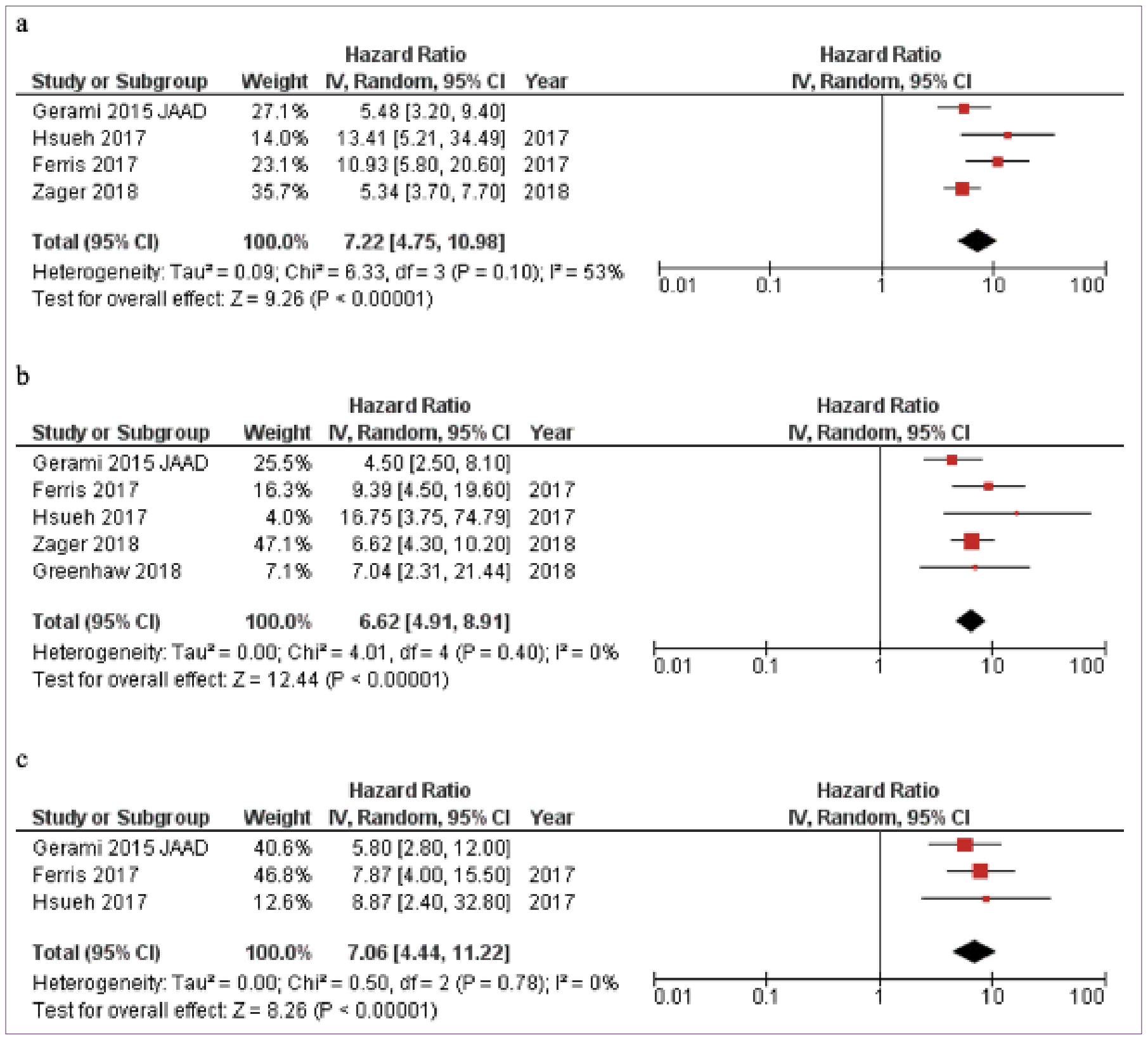

May 2020 Volume 4 Issue 3 
Figure 3. Forest plot of odds ratio and $95 \% \mathrm{Cl}$ for (a) recurrence, (b) distant metastasis, (c) overall survival, and (d) sentinel lymph node biopsy positivity.

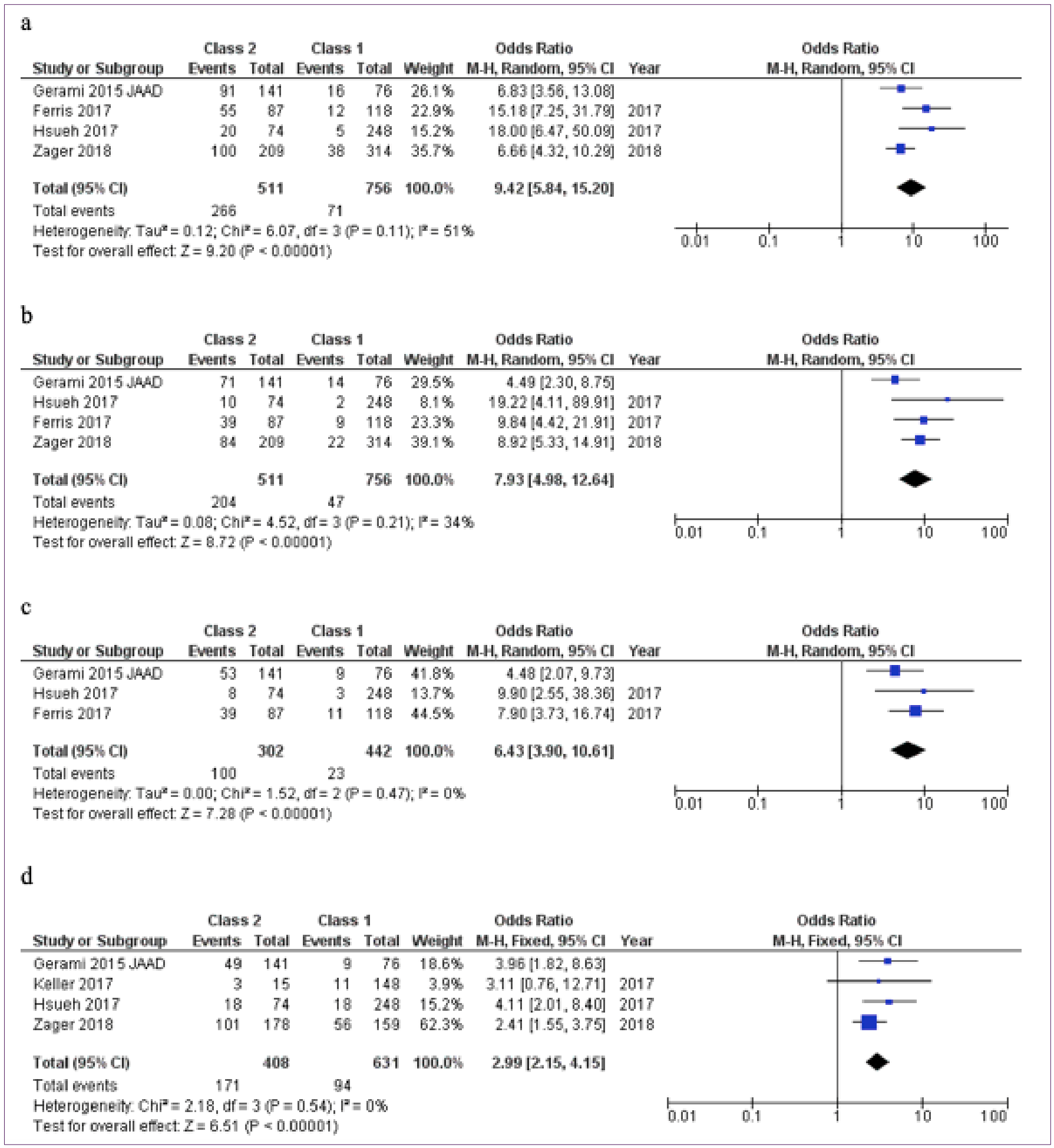

May 2020 Volume 4 Issue 3 
role in honing risk predictions. Adding GEP testing in clinical trials as a stratifying characteristic may also better randomize patients with different baseline risks of metastasis.

There are also several diagnostic challenges common to melanoma management that can be ameliorated by GEP testing. For example, it can be difficult to determine whether a patient should undergo SLNB for thin tumors, tumors with unknown thickness (shaved through the base), or older persons with lower rates of SLNB positivity. A high-risk GEP result may appropriately influence a clinician to refer a patient for this procedure. Current NCCN guidelines suggest that patients with a $5 \%$ risk of positive SLNB should undergo SLNB. ${ }^{32}$ Although GEP testing may help stratify patient risk for SLNB positivity, GEP is not currently recommended to replace SLNB as evidenced by the results of this review.

Limitations were present in this systematic review and meta-analysis. Most included studies were conducted retrospectively versus prospectively. Although a comprehensive search strategy was employed, missing relevant studies may be unavoidable, especially those published in non-English language journals. Some studies did not directly provide HRs with corresponding effect sizes requiring manual derivation from Kaplan-Meier survival curves. Significant heterogeneity was noted when calculating the pooled HR for RFS and the pooled OR for recurrence. Also, several permutations of different melanoma gene profiles are being tested and developed. However, these new technologies are still early in their development and additional studies may impact on potential uses and adoption.
In conclusion, the findings of this review have clinical implications for patients with melanoma to better assess their prognosis leading to more effective management of their disease. The results of this study may be useful when deciding to offer GEP testing to primary cutaneous melanoma patients.

\section{METHODS}

\section{Search Strategy}

This systematic review and meta-analysis followed the Preferred Reporting Items for Systematic Reviews and Meta-Analyses (PRISMA) guidelines (Prospero registration no. CRD42018110114). Electronic searches were performed in three databases for articles published from inception to September 24, 2018: Pubmed MEDLINE, Cochrane Library CENTRAL, and Embase. Search terms included: "Gene Expression Profile," "Cutaneous Melanoma," "Prognosis," "Risk," "Predict," "31 gene," "53 gene," and "9 gene" (Supplementary Materials and Methods). Reference lists of all included studies and recent reviews were also assessed. Ongoing clinical trials and unpublished studies were identified through ClinicalTrials.gov.

\section{Inclusion Criteria}

All studies related to gene expression profiling or gene signatures in the prognosis of primary cutaneous melanoma patients. Studies were required to measure prognostic validity, analytical validity, or clinical impact of GEP.

\section{Exclusion Criteria}

Case reports, review articles, articles with less than 10 samples, unpublished articles, and animal studies were excluded. Use of GEP in vitro, on non-human samples, and in silico reports were not included. All studies done on non-primary melanomas were May 2020 Volume 4 Issue 3 
excluded. Non-English studies were excluded.

\section{Outcome Measures}

The prognostic validity, analytical validity, and/or clinical impact of GEP was determined. The relationship between GEP and survival outcomes (recurrence-free survival (RFS), distant metastasis-free survival (DMFS), melanoma-specific survival (MSS), or overall survival (OS)) was measured using hazard ratios with confidence intervals, Kaplan Meier curves with survival estimates, Cox univariate or multivariate analysis, or accuracy metrics for risk prediction.

\section{Data extraction and Quality Appraisal}

All data were extracted from article text, tables, and figures. Two reviewers (G.P. and R.T.) independently screened and reviewed each article for inclusion. Each reviewer independently extracted data and discrepancies were resolved by discussion and consensus. If Kaplan-Meier graphs were provided without the hazard effect or $95 \% \mathrm{Cl}$, these were estimated using previously described methods. ${ }^{33}$ Risk of bias was assessed using the Cochrane QUIPS tool ${ }^{34}$ for assessing risk of bias in prognostic factor studies. (Figure S1)

\section{Statistical Analysis}

All statistical analyses were performed using Review Manager, version 5.3 (Cochrane Collaboration, Software Update). The statistical heterogeneity between the included studies was assessed by the $1^{2}$ statistic $\left(I^{2}=0-25 \%\right.$, no heterogeneity; $\mathrm{I}^{2}=$ $25-50 \%$, moderate heterogeneity; $1^{2}=50$ $75 \%$, large heterogeneity; $\left.\right|^{2}=75-100 \%$, extreme heterogeneity). A funnel plot was used to assess for publication bias. A random effects model was used to take into account the possible diversity and methodological variation among studies. Summary statistics are presented as hazard ratios $(\mathrm{HR})$ or odds ratios (OR) as appropriate. All $P$ values were 2-sided, and statistical significance was set at $\mathrm{P}<.05$.

Conflict of Interest Disclosures: Dr. Darrell Rigel is a consultant for Castle Biosciences. Dr. Graham Litchman and Dr. Giselle Prado are fellows of the National Society for Cutaneous Medicine which receives grants from Castle Biosciences.

Funding: None

Corresponding Author:

Graham H. Litchman, DO, MS

35 E 35th St. \#208

New York, NY, 10016, USA

Phone: 203-940-0373

Email: graham.litchman@gmail.com

References:

1. Siegel RL, Miller KD, Jemal A. Cancer statistics, 2019. CA Cancer J Clin. 2019;69(1):7-34. NCCN Clinical Practice Guidelines in Oncology. Melanoma. Version 3.2018. Published July 12, 2018.

2. Alonso SR, Tracey L, Ortiz P, et al. A highthroughput study in melanoma identifies epithelial-mesenchymal transition as a major determinant of metastasis. Cancer Res. 2007;67(7):3450-60.

3. Winnepenninckx V, Lazar V, Michiels S, et al. Gene expression profiling of primary cutaneous melanoma and clinical outcome. J Natl Cancer Inst. 2006;98(7):472-82.

4. Conway C, Mitra A, Jewell R, et al. Gene expression profiling of paraffin-embedded primary melanoma using the DASL assay identifies increased osteopontin expression as predictive of reduced relapse-free survival. Clin Cancer Res. 2009;15(22):6939-46.

5. Jewell R, Conway C, Mitra A, et al. Patterns of expression of DNA repair genes and relapse from melanoma. Clin Cancer Res. 2010;16(21):521121.

6. Harbst K, Staaf J, Lauss M, et al. Molecular profiling reveals low- and high-grade forms of primary melanoma. Clin Cancer Res. 2012;18(15):4026-36.

7. Jonsson G, Busch C, Knappskog S, Geisler J, Miletic $\mathrm{H}$, Ringner M, et al. Gene expression profiling-based identification of molecular May 2020 Volume 4 Issue 3 
subtypes in stage IV melanomas with different clinical outcome. Clin Cancer Res 2010;16:335667.

8. Nsengimana J, Laye J, Filia A, et al. Independent replication of a melanoma subtype gene signature and evaluation of its prognostic value and biological correlates in a population cohort. Oncotarget. 2015;6(13):11683-93.

9. Badal B, Solovyov A, Di cecilia S, et al. Transcriptional dissection of melanoma identifies a high-risk subtype underlying TP53 family genes and epigenome deregulation. JCI Insight. 2017;2(9)

10. Meyer S, Fuchs TJ, Bosserhoff AK, et al. A seven-marker signature and clinical outcome in malignant melanoma: a large-scale tissuemicroarray study with two independent patient cohorts. PLoS ONE. 2012;7(6):e38222.

11. Brunner $G$, Reitz M, Heinecke A, et al. A ninegene signature predicting clinical outcome in cutaneous melanoma. J Cancer Res Clin Oncol. 2013;139(2):249-58.

12. Brunner G, Gambichler T, Reinhold U, et al. A prognostic gene expression profile complements staging of thin fatal melanomas and melanomas with known sentinel lymph node status. Oncol Res Treat. 2018;41(S1):162.

13. Sivendran S, Chang R, Pham L, et al. Dissection of immune gene networks in primary melanoma tumors critical for antitumor surveillance of patients with stage II-III resectable disease. J Invest Dermatol. 2014;134(8):2202-2211.

14. Cook RW, Middlebrook B, Wilkinson J, et al. Analytic validity of DecisionDx-Melanoma, a gene expression profile test for determining metastatic risk in melanoma patients. Diagn Pathol. 2018;13(1):13.

15. Berger AC, Davidson RS, Poitras JK, et al. Clinical impact of a 31-gene expression profile test for cutaneous melanoma in 156 prospectively and consecutively tested patients. Curr Med Res Opin. 2016;32(9):1599-604.

16. Dengel LT, Hickman AW, Slingluff CL. Effect of gene expression profile (GEP) testing on clinical management in $19 \%$ of consecutively treated patients with stage IB/IIA melanoma at a single institution. J Clin Oncol. 2017; 35 (suppl; abstr e21080)

17. Schuitevoerder D, Heath M, Cook RW, et al. Impact of Gene Expression Profiling on DecisionMaking in Clinically Node Negative Melanoma Patients after Surgical Staging. J Drugs Dermatol. 2018;17(2):196-199.

18. Cook RW, Glazer A, Middlebrook B, et al. Clinical impact of a 31-gene expression profile test on guidance of sentinel lymph node biopsy, imaging and oncology referral. Pigment Cell Melanoma Res. 2017;30(1):92.

19. Farberg AS, Glazer AM, White R, Rigel DS. Impact of a 31-gene Expression Profiling Test for Cutaneous Melanoma on Dermatologists' Clinical Management Decisions. J Drugs Dermatol. 2017;16(5):428-431.

20. Svoboda RM, Glazer AM, Farberg AS, Rigel DS. Factors Affecting Dermatologists' Use of a 31Gene Expression Profiling Test as an Adjunct for Predicting Metastatic Risk in Cutaneous Melanoma. J Drugs Dermatol. 2018;17(5):544547.

21. Gerami P, Cook RW, Wilkinson J, et al. Development of a prognostic genetic signature to predict the metastatic risk associated with cutaneous melanoma. Clin Cancer Res. 2015;21(1):175-83.

22. Gerami P, Cook RW, Russell MC, et al. Gene expression profiling for molecular staging of cutaneous melanoma in patients undergoing sentinel lymph node biopsy. J Am Acad Dermatol. 2015;72(5):780-5.e3.

23. Cook RW, Covington KR, Monzon FA. Continued evaluation of a 31-gene expression profile to predict metastasis in an expanded cohort of 782 cutaneous melanoma patients. Pigment Cell Melanoma Res. 2017;30:e73.

24. Ferris LK, Farberg AS, Middlebrook B, et al. Identification of high-risk cutaneous melanoma tumors is improved when combining the online American Joint Committee on Cancer Individualized Melanoma Patient Outcome Prediction Tool with a 31-gene expression profilebased classification. J Am Acad Dermatol. 2017;76(5):818-825.e3.

25. Zager JS, Gastman BR, Leachman S, et al. Performance of a prognostic 31-gene expression profile in an independent cohort of 523 cutaneous melanoma patients. BMC Cancer. 2018;18(1):130.

26. Greenhaw BN, Zitelli JA, Brodland DG. Estimation of Prognosis in Invasive Cutaneous Melanoma: An Independent Study of the Accuracy of a Gene Expression Profile Test. Dermatol Surg. 2018;

27. Hsueh EC, Debloom JR, Lee J, et al. Interim analysis of survival in a prospective, multi-center registry cohort of cutaneous melanoma tested with a prognostic 31-gene expression profile test. J Hematol Oncol. 2017;10(1):152.

28. Keller JK, Schwartz T, Lizalek JM, Hsueh EC. Utility of Gene Expression Profiling in Determining Necessity of Sentinel Node Biopsy in Melanoma. Ann Surg Oncol. 2017;24(S1):S148.

May 2020 Volume 4 Issue 3 
29. Huang X, Hewgley WP, Guerrero W, Fleming M. Application of Gene Expression Profiling in the Management of Cutaneous Melanoma. Ann Surg Oncol. 2017;24(S1):S144.

30. Cook RW, Covington KR, Monzon FA. Prognostic value of non-sentinel lymph node (non-SLN) status and a prognostic 31-gene expression profile (GEP) in stage III cutaneous melanoma patients Pigment Cell Melanoma Res. 2018;31:e144.

31. Keller J, Schwartz T, Lizalek J, Hsueh E. Exploring the Role of Gene Expression Profiling in the Prediction of Non-Sentinel Node Status in Cutaneous Melanoma. Ann Surg Oncol. 2018;24(S1):S67.

32. National Comprehensive Cancer Network. NCCN Clinical Practice Guidelines in Oncology:

Cutaneous Melanoma. 2019.
33. Tierney JF, Stewart LA, Ghersi D, Burdett S, Sydes MR. Practical methods for incorporating summary time-to-event data into meta-analysis. Trials. 2007;8:16. doi:10.1186/1745-6215-8-16.

34. Hayden JA, Van der windt DA, Cartwright JL, Côté P, Bombardier C. Assessing bias in studies of prognostic factors. Ann Intern Med. 2013;158(4):280-6. 


\section{SUPPLEMENTAL MATERIALS \& METHODS}

Figure S1. Risk of bias summary.

\begin{tabular}{|c|c|c|c|c|c|c|c|}
\hline & 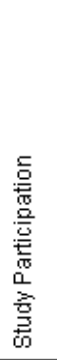 & 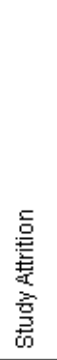 & 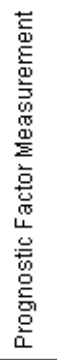 & 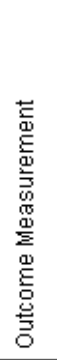 & 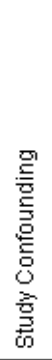 & 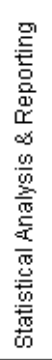 & 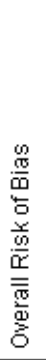 \\
\hline Alonso 2007 & $\odot$ & $\odot$ & + & $\odot$ & & $\odot$ & $\odot$ \\
\hline Badal 2017 & 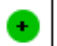 & + & + & + & & $\odot$ & $\odot$ \\
\hline Berger 2016 & + & & + & + & & $\odot$ & $\odot$ \\
\hline Brunner 2013 & + & + & + & + & & $\odot$ & $\odot$ \\
\hline Brunner 2018 & & & + & + & & & \\
\hline Conway 2009 & + & + & $\Theta$ & + & & $\odot$ & \\
\hline Cook 2016 & + & & + & + & & & \\
\hline Cook 2017 & + & & + & & & + & \\
\hline Cook 2018 & + & + & + & + & & + & \\
\hline Cook 2018 Non-SLN & & & + & & & & \\
\hline Dengel 2017 & 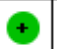 & + & + & 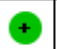 & & & \\
\hline Farberg 2017 & + & + & + & + & & $\odot$ & $\odot$ \\
\hline Ferris 2017 & + & + & + & + & & $\odot$ & $\odot$ \\
\hline Gerami $2015 \mathrm{CCR}$ & + & + & + & + & & $\odot$ & + \\
\hline Gerami 2015 JAAD & + & + & + & + & & + & \\
\hline Greenhaw 2018 & + & + & + & + & & + & \\
\hline Harbst 2012 & + & + & + & + & & $\odot$ & $\odot$ \\
\hline Hsueh 2017 & + & + & + & + & & $\odot$ & $\odot$ \\
\hline Huang 2017 & & + & + & & & & \\
\hline Jewell 2010 & + & + & $\odot$ & + & & $\odot$ & \\
\hline Keller 2017 & + & + & + & + & & $\odot$ & + \\
\hline Keller 2018 & & + & + & + & & + & \\
\hline Meyer 2012 & + & & + & + & & + & + \\
\hline Nsengimana 2015 & + & + & + & + & & $\odot$ & $\odot$ \\
\hline Schuitevoerder 2018 & + & + & + & + & & & \\
\hline Sivendran 2014 & + & + & + & + & & + & + \\
\hline Svoboda 2018 & + & + & + & + & + & + & + \\
\hline Winnepenninckx 2006 & 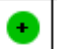 & + & + & + & & $\odot$ & $\odot$ \\
\hline Zager 2018 & + & + & + & + & & $\odot$ & \\
\hline
\end{tabular}




\section{PUBMED}

\#43 Add Search ((\#1 OR \#2 OR \#8 OR \#10 OR \#11) AND (\#3) AND (\#6 OR \#7 OR \#9) NOT (\#17 OR \#21 OR \#24 OR \#26 OR \#27 OR \#28 OR \#30 OR \#31 OR \#32 OR \#33 OR \#37))) Filters: Publication date from $2003 / 01 / 01$ to $2018 / 09 / 24 \quad 422 \quad 09: 51: 40$

\#42 Add Search ((\#1 OR \#2 OR \#8 OR \#10 OR \#11) AND (\#3) AND (\#6 OR \#7 OR \#9) NOT (\#17 OR \#21 OR \#24 OR \#26 OR \#27 OR \#28 OR \#30 OR \#31 OR \#32 OR \#33 OR \#37))) $440 \quad$ 09:35:07

\#41 Add Search (((\#1 OR \#2 OR \#8 OR \#10 OR \#11) AND (\#3) AND (\#6 OR \#7 OR \#9) NOT (\#17 OR \#21 OR \#24 OR \#26 OR \#27 OR \#28 OR \#30 OR \#31 OR \#32 OR \#33 OR \#37)) Filters: Publication date from 2003/01/01 to 2018/09/24) Schema: all $0 \quad 09: 34: 42$

\#40 Add Search (((\#1 OR \#2 OR \#8 OR \#10 OR \#11) AND (\#3) AND (\#6 OR \#7 OR \#9) NOT (\#17 OR \#21 OR \#24 OR \#26 OR \#27 OR \#28 OR \#30 OR \#31 OR \#32 OR \#33 OR \#37)) Filters: Publication date from $2003 / 01 / 01$ to $2018 / 09 / 24) \quad 0 \quad 09: 34: 41$

\#39 Add Search (((\#1 OR \#2 OR \#8 OR \#10 OR \#11) AND (\#3) AND (\#6 OR \#7 OR \#9) NOT (\#17 OR \#21 OR \#24 OR \#26 OR \#27 OR \#28 OR \#30 OR \#31 OR \#32 OR \#33 OR \#37)) Filters: Publication date from 2003/01/01 to 2018/09/24) Schema: all Filters: Publication date from 2003/01/01 to 2018/09/24 $0 \quad$ 09:34:37

\#38 Add Search (((\#1 OR \#2 OR \#8 OR \#10 OR \#11) AND (\#3) AND (\#6 OR \#7 OR \#9) NOT (\#17 OR \#21 OR \#24 OR \#26 OR \#27 OR \#28 OR \#30 OR \#31 OR \#32 OR \#33 OR \#37)) Filters: Publication date from 2003/01/01 to 2018/09/24) Filters: Publication date from 2003/01/01 to 2018/09/24 $0 \quad 09: 34: 36$

\#37 Add Search ovarian Filters: Publication date from 2003/01/01 to 2018/09/24 97464 09:34:14

\#36 Add Search ((\#1 OR \#2 OR \#8 OR \#10 OR \#11) AND (\#3) AND (\#6 OR \#7 OR \#9) NOT (\#17 OR \#21 OR \#24 OR \#26 OR \#27 OR \#28 OR \#30 OR \#31 OR \#32 OR \#33)) Filters: Publication date from 2003/01/01 to 2018/09/24 $428 \quad 09: 33: 47$

\#34 Add Search ((\#1 OR \#2 OR \#8 OR \#10 OR \#11) AND (\#3) AND (\#6 OR \#7 OR \#9) NOT (\#17 OR \#21 OR \#24 OR \#26 OR \#27 OR \#28 OR \#30 OR \#31 OR \#32 OR \#33)) $446 \quad$ 09:32:40

\#35 Add Search ((\#1 OR \#2 OR \#8 OR \#10 OR \#11) AND (\#3) AND (\#6 OR \#7 OR \#9) NOT (\#17 OR \#21 OR \#24 OR \#26 OR \#27 OR \#28 OR \#30 OR \#31 OR \#32 OR \#33)) Filters: Publication date from 1998/01/01 to 2018/09/24 $442 \quad 09: 32: 31$

\begin{tabular}{|c|c|c|c|c|c|}
\hline 33 & Add & Search animal & \multicolumn{2}{|c|}{6432853} & $09: 31: 27$ \\
\hline 32 & Add & Search mouse & \multicolumn{2}{|c|}{1628782} & $09: 31: 23$ \\
\hline 1 & Add & \multicolumn{2}{|c|}{ Search colorectal } & \multicolumn{2}{|c|}{152692 09:31:18 } \\
\hline & Add & \multicolumn{4}{|c|}{ Search RENAL 646112 09:31:11 } \\
\hline 99 & $\begin{array}{l}\text { Add } \\
\text { OR \#26 }\end{array}$ & \multicolumn{4}{|c|}{$\begin{array}{l}\text { Search }((\# 1 \text { OR \#2 OR \#8 OR \#10 OR \#1 } \\
6 \text { OR \#27 OR \#28)) } 544 \quad 09: 31: 05\end{array}$} \\
\hline & Add & \multicolumn{2}{|c|}{ Search hepatocellular } & 114 & 74 09:29:30 \\
\hline & Add & Search lung & \multicolumn{3}{|c|}{832619 09:29:24 } \\
\hline & Add & Search breast & \multicolumn{3}{|c|}{462402 09:29:18 } \\
\hline
\end{tabular}




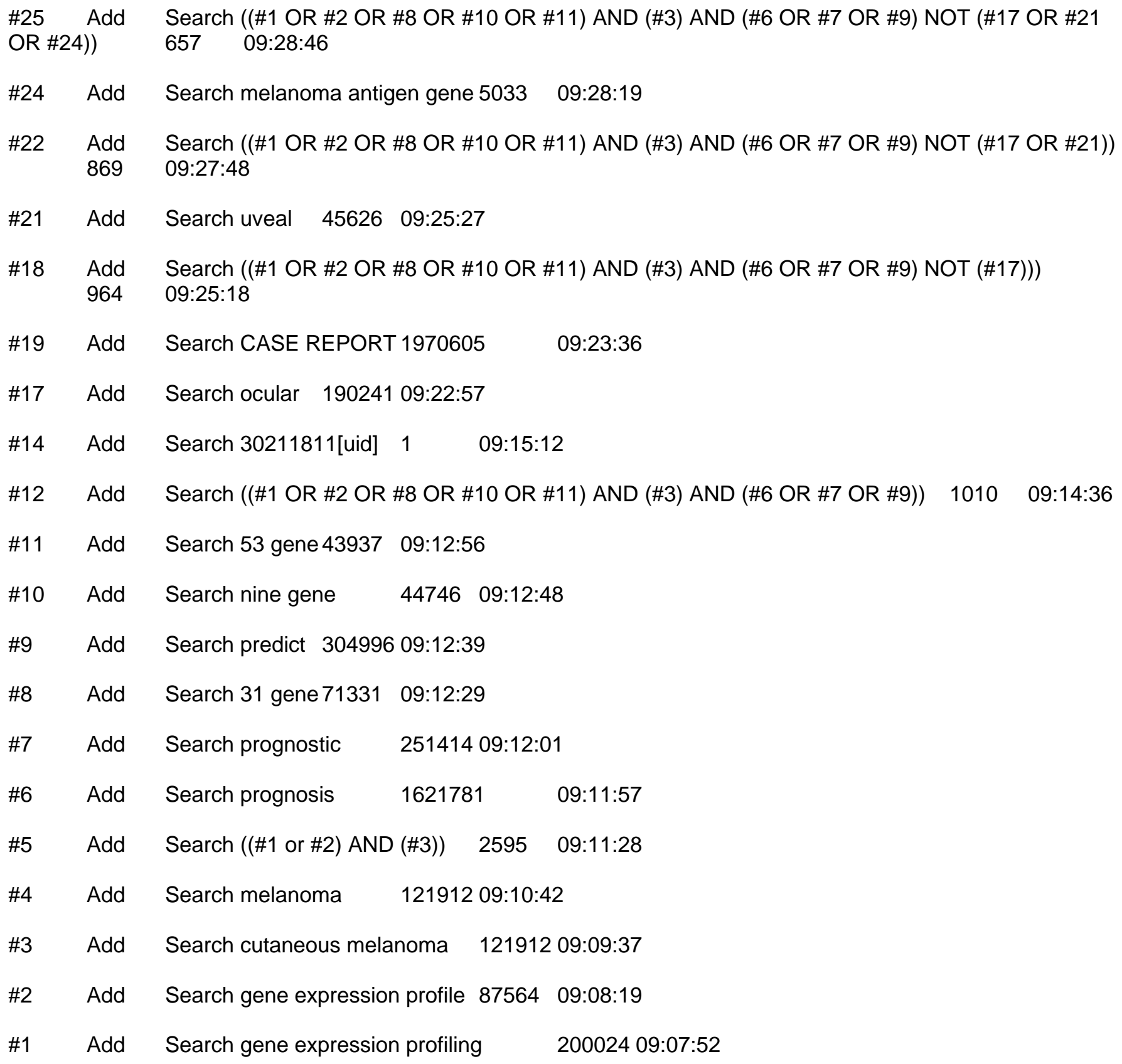




\section{COCHRANE}

\begin{tabular}{|c|c|c|c|c|c|c|c|}
\hline & + & & & & \multicolumn{2}{|c|}{ View fewer lines } & Print \\
\hline- & + & \#1 & gene expression profile & S- & $\mathrm{MeSH}-$ & $\mathbf{T}$ & 1354 \\
\hline - & + & \#2 & gene expression profiling & & & $\mathbf{T}$ & 1183 \\
\hline- & + & \#3 & cutaneous melanoma & & & $\mathbf{T}$ & 507 \\
\hline- & + & $\# 4$ & 53 gene & & & $\mathbf{T}$ & 2073 \\
\hline- & + & \#5 & nine gene & & & $\boldsymbol{T}$ & 1228 \\
\hline- & + & $\# 6$ & 31 gene & & & $\boldsymbol{T}$ & 16372 \\
\hline- & + & $\# 7$ & prognosis & & & $\boldsymbol{T}$ & 28272 \\
\hline- & + & $\# 8$ & prognostic & & & $\mathbf{T}$ & 15973 \\
\hline- & + & $\# 9$ & risk & & & $\boldsymbol{T}$ & 180866 \\
\hline - & + & $\# 10$ & predict & & & $\mathbf{T}$ & 17318 \\
\hline- & + & $\# 11$ & $(\# 1$ OR \#2 OR 4 OR \#5 OR \#6) AND (\#3) AND (\#7 OR \#8 OR \#9 OR\#10) & & & $\mathbf{T}$ & 154 \\
\hline- & + & $\# 12$ & Manually type a search term here or click on the S (Search Wizard) or MeSH button to compose one & S - & $\mathrm{MeSH}-$ & $\mathbf{T}$ & N/A \\
\hline
\end{tabular}

\section{EMBASE}

\# Searches
10 ((gene expression profiling or 31 gene or nine gene or 53 gene) and cutaneous melanoma and (prognosis or risk)).at

( $\# 1$ or $\# 6$ or $\# 7$ or \#8) and \#3 and \#5) a

853 gene.mp.

7 nine gene.mp.

631 gene.mp.

exp prognosis/ or exp riskl

4 exp prognosisl

exp cutaneous melanoma/

exp gene expression profiling!

exp gene expression profiling 